\title{
Percepção de aprendizado dos discentes da UFPA durante o ensino remoto
}

DOI: 10.37702/2175-957X.COBENGE.2021.3649

tales henrique almeida vaz pereira rocha - tales.rocha@itec.ufpa.br Universidade Federal do Pará rua da mata 82

66615-420 - Belém - PA

José Cristhian Mendes Saldanha - josecristhian7@gmail.com Universidade Federal do Pará

Rua sétima, CJ Guajará II 20

67143-810 - Ananindeua - PA

Gabriel de Carvalho Neves - gabrielcarvalho804804@gmail.com Universidade Federal do Pará

Av. Governador José Malcher 1423

66055-260 - Belém - PA

Jamille Brito Borges - jamillebborges@hotmail.com

Universidade Federal do Pará

Travessa WE-42 (Cidade Nova VIII) 252

67133-250 - Ananindeua - PA

Nívea G B Albuquerque - nivea@ufpa.br

UFPA

C) IMPERIO AMAZONICO 15

66613-080 - BELEM - PA

Resumo: Durante a perduração da pandemia da COVID-19, a Universidade Federal do Pará adotou medidas para a continuação das aulas em modelo remoto. Isso consistiu em adequar diversos parâmetros aos meios virtuais, tanto por parte da universidade quanto pelos professores e estudantes, sem que houvesse um tempo considerado hábil para tal. Assim, este artigo buscou entender como os discentes estão lidando com esse novo cenário da educação superior, bem como explicar quais fatores mais influenciam seu desempenho, positiva ou negativamente. Após analisar as respostas dos discentes nos seis parâmetros 


\section{COBENGE de Educação em Engenharia

estudados, as conclusões foram que o Ensino Remoto Emergencial (ERE) foi considerado medianamente adaptado pelos autores, tendo em vista que esta já está ocorrendo, mas ainda não atingiu sua totalidade.

Palavras-chave: Ensino Remoto. Pandemia. COVID-19. Desempenho 


\section{PERCEPÇÃO DE APRENDIZADO DOS DISCENTES DA UFPA DURANTE O ENSINO REMOTO}

Resumo: Durante a perduração da pandemia da COVID-19, a Universidade Federal do Pará adotou medidas para a continuação das aulas em modelo remoto. Isso consistiu em adequar diversos parâmetros aos meios virtuais, tanto por parte da universidade quanto pelos professores e estudantes, sem que houvesse um tempo considerado hábil para tal. Assim, este artigo buscou entender como os discentes estão lidando com esse novo cenário da educação superior, bem como explicar quais fatores mais influenciam seu desempenho, positiva ou negativamente. Após analisar as respostas dos discentes nos seis parâmetros estudados, as conclusões foram que o Ensino Remoto Emergencial (ERE) foi considerado medianamente adaptado pelos autores, tendo em vista que esta já está ocorrendo, mas ainda não atingiu sua totalidade.

Palavras-Chave: Ensino Remoto. Pandemia. COVID-19. Desempenho.

\section{INTRODUÇÃO}

No final primeiro trimestre de 2020 o Brasil começou a sentir os impactos da pandemia do coronavírus, segundo o relatório da Organização para cooperação e Desenvolvimento Econômico (OCDE) "Education at a glance", a educação foi fortemente impactada devido às interrupções nos meses seguintes, forçando aos educadores a pensar em maneiras de dar continuidade no ensino, além de ressaltar que os alunos também passaram por esse processo de adaptação ao novo ambiente de ensino.

Tendo em vista esse cenário a Universidade Federal do Pará (UFPA) aprovou o modelo de Ensino Remoto Emergencial (ERE) em agosto de 2020, estabelecendo um período letivo de setembro até fevereiro, sendo este com algumas excepcionalidades considerando as condições adversas em que o ensino seria praticado, tornando opcional aos alunos cursarem esse período e aliviando as penalidades para as desistências das componentes curriculares ofertadas.

Os autores do presente trabalho buscaram entender a experiência dos discentes que aceitaram continuar a graduação mesmo em condições tão atípicas, esclarecendo suas dificuldades, sua adesão às medidas assistencialista ofertadas pela instituição e principalmente se a transição entre o ensino presencial e remoto criou um ambiente favorável para a absorção do conteúdo ministrado.

\subsection{Objetivo}

Este trabalho tem por objetivo entender os aspectos que o ensino emergencial remoto e suas particularidades causaram no rendimento acadêmico dos alunos e quais outros fatores relacionados ao contexto do período vivido impactaram as disciplinas cursadas pelos alunos de graduação da UFPA. 


\section{METODOLOGIA}

O método utilizado no presente trabalho foi uma coleta de dados por meio da Escala Likert, que possibilita a mensuração de dados psicológicos em dados numéricos (LIKERT, 1932).

Portanto, foi feito um estudo prévio acerca dos principais fatores do ensino que teriam relação direta e indireta entre o ensino remoto, o isolamento social e a aprendizagem dos alunos, focando na realidade específica dos estudantes de Engenharia Civil da Universidade Federal do Pará.

Utilizamos como base os aspectos que a própria universidade utiliza para avaliar o rendimento semestral dos professores nos quesitos posicionamento na disciplina, avaliações e materiais. Além disso, exploramos soft skills e outros aspectos mais sutis que foram detectadas nas experiências de discentes dos autores.

Todos estes fatores resultaram nos dois pilares a seguir do formulário:

\subsection{Adaptação dos professores}

Em um relatório técnico realizado pela Universidade Federal de Minas Gerais (UFMG) e pela Confederação Nacional dos Trabalhadores em Educação (CNTE), foi feita uma pesquisa com professores da rede pública de ensino, que explicitou que apenas $1 \mathrm{a}$ cada 10 professores já tinham experiência com o ensino remoto ou a distância.

Isso deixa claro que as metodologias utilizadas pelos professores não são apropriadas para este formato de ensino, precisando de reformulação ou de adaptação. Este pilar de nossa metodologia buscou recolher dados acerca do quão efetiva foi esta adaptação em poucos meses, e até mesmo se ela ocorreu.

Para isso, utilizamos perguntas sobre metodologia, avaliações, materiais didáticos e presença de monitores facilitando a aprendizagem e a utilização de plataformas digitais.

\subsection{Desempenho do estudante}

Este pilar da metodologia se dedicou a sondar o desenvolvimento do estudante nos quesitos disciplina, foco e rendimento geral. Afinal, o ensino regular brasileiro falha em ensinar soft skills que vão ajudar o estudante a manter seu aprendizado de forma mais independente e ativa, sem a presença próxima de um professor que vá tutorar e manter a atenção do aluno.

Muitas vezes os alunos precisam aprender estas habilidades de forma autodidata, e buscamos mensurar nesta parte do formulário até onde os estudantes de engenharia estão capacitados para isso.

\section{RESULTADOS}

Com base na análise das informações coletadas pelos discentes que participaram do Ensino Remoto Emergencial, foram realizadas diversas correlações que formam o entendimento de como se deu o aproveitamento destes e de que maneira eles foram influenciados pela pandemia.

Considerando os aspectos supracitados tópico de metodologia, para critério de avaliação, foram considerados como avaliações positivas apontamentos nos campos 4 e 5 do formulário, os grupos 1 e 2 foram considerados detratores para a pesquisa e o grupo 3 foram avaliações desconsideradas. 


\subsection{Adaptação dos professores}

Ao elaborar o questionário de pesquisa, os autores planearam obter dados suficientes para avaliar o Ensino Remoto e definir o grau de adaptação dos docentes a este novo cenário.

Em discussões realizadas no período de desenvolvimento do formulário os autores julgaram ser interessante que os alunos indicassem o quanto a metodologia dos professores em sala foi construtiva para seu aprendizado, tanto na clareza de sua explicação do conteúdo ministrado, quanto no repasse de informações importantes para o prosseguimento da disciplina, o que é informado na Figura 01 abaixo.

Figura 01 - Avaliação dos discentes quanto à metodologia das aulas dos docentes

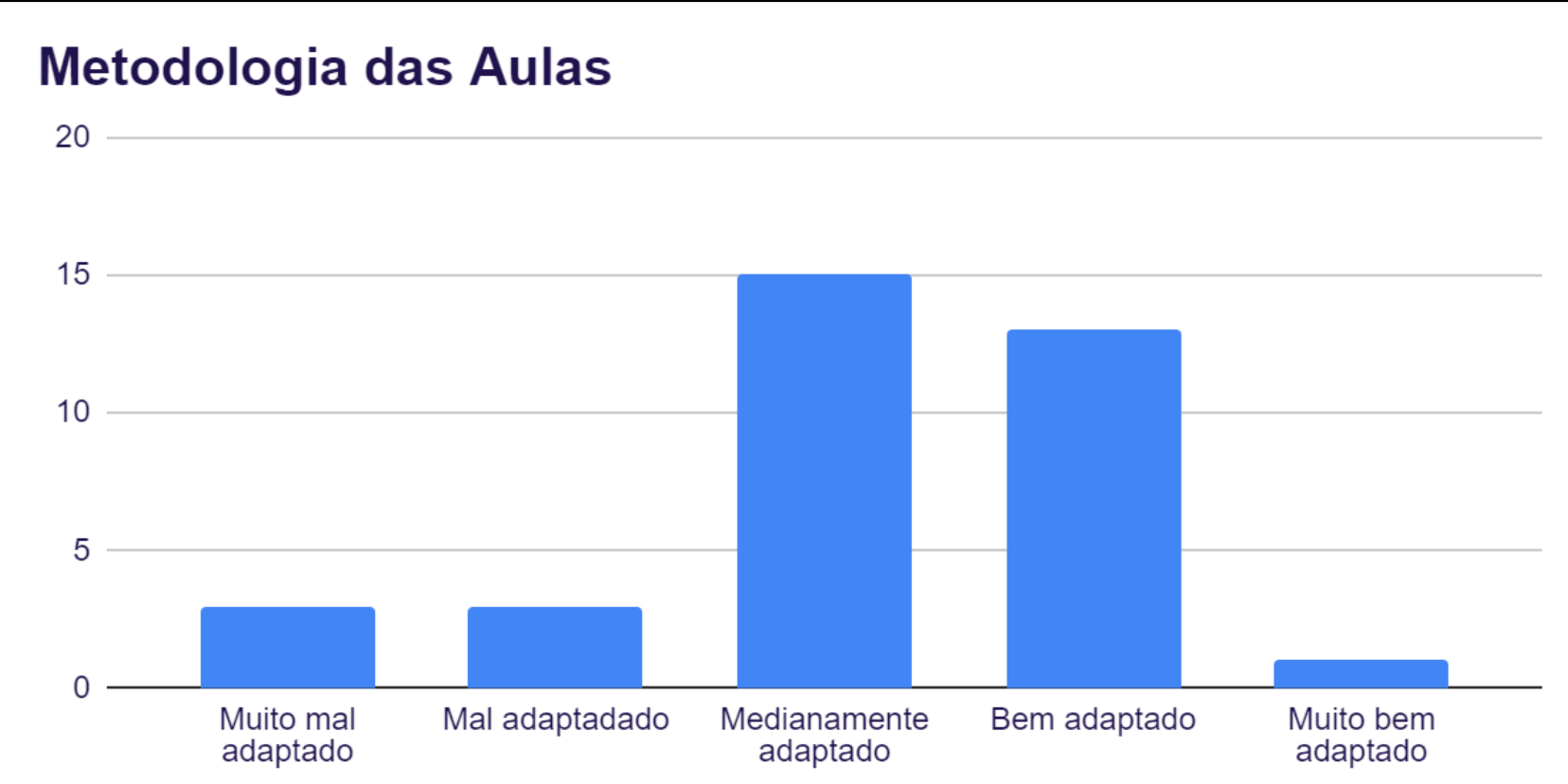

Fonte: Os autores, 2021

Analisando as respostas indicadas e sua representação gráfica é observada uma certa aprovação no aspecto referente a construção do canal docente-discente, com um percentual de $40,0 \%$ de avaliações positivas, tendo como base o critério adotado pelos autores. É interessante notar que a maioria das respostas atribuíram o conceito "medianamente adaptado", que na visão dos autores não contribuem para avaliações positivas deste parâmetro.

Considerando os aspectos assíncronos do sistema de ensino remoto proposto pela instituição, a disponibilização de um material didático de apoio ao conteúdo exposto em sala de aula é fundamental para uma jornada de conhecimento construtiva para os alunos, sendo assim os estudantes foram consultados a esse respeito e as respostas foram organizadas na Figura 02. 
Figura 02 - Avaliação dos discentes quanto ao material dos docentes em aula

\section{Material}

20

15

10

Muito mal

adaptado

Mal adaptadado

Medianamente adaptado

Bem adaptado

Muito bem adaptado

Fonte: Os autores, 2021

Atribuindo a têmpera considerada é perceptível uma aceitação considerável, sendo ligeiramente maior que $50 \%$, sendo assim, os materiais disponibilizados pelos docentes foram avaliados positivamente.

Quanto as avaliações e testes, estas são a culminância do conteúdo absorvido pelos discentes, proporcionando uma oportunidade de os cursistas praticarem em um ambiente controlado as praxes da disciplina, devido a isso os autores pensaram ser esse um aspecto relevante para o questionamento da pesquisa.

Figura 03 - Avaliação dos discentes quanto aos métodos avaliativos dos docentes

\section{Avaliações}

20

15

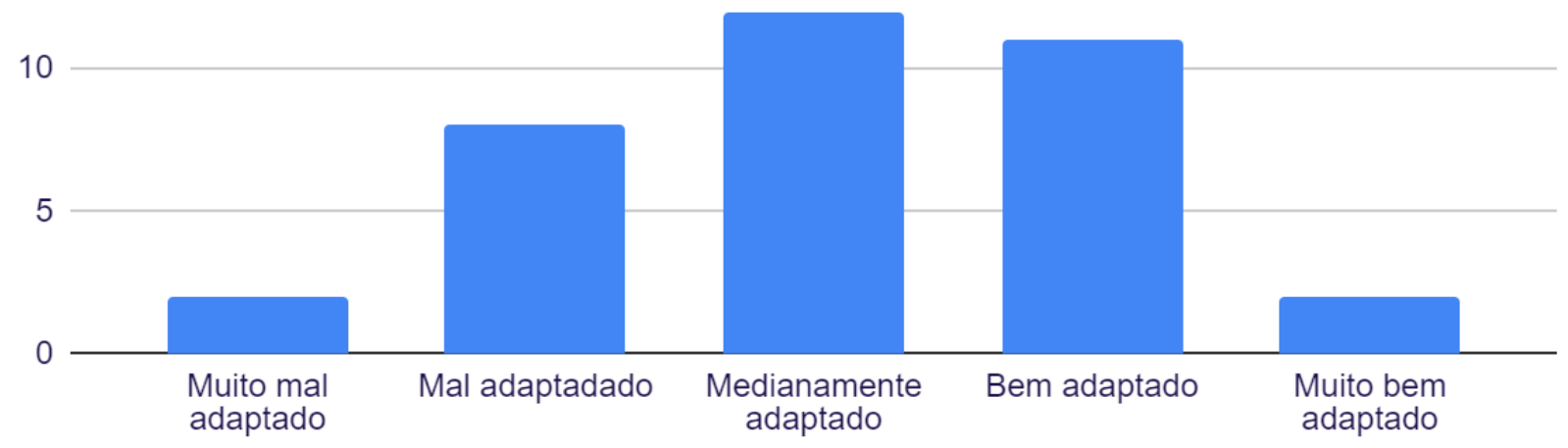

Fonte: Os autores, 2021 
É notada na Figura 03 acima uma taxa inferior aos pontos supracitados resultando em um índice de aprovação menor que $40 \%$, portanto é visível uma necessidade de repensar a maneira de aplicação destas provas.

Os monitores realizam um papel de facilitadores para os alunos, tanto na comunicação com o docente quanto na absorção no conteúdo e execução das atividades de fixação. O programa de monitoria continuou durante o ensino remoto, com o objetivo de auxiliar os alunos fora das salas de aula remotas, com reuniões extras e conversas por meio de aplicativos de comunicação.

Figura 04 - Avaliação dos discentes quanto aos monitores dos docentes

\section{Monitores}

20 15

10

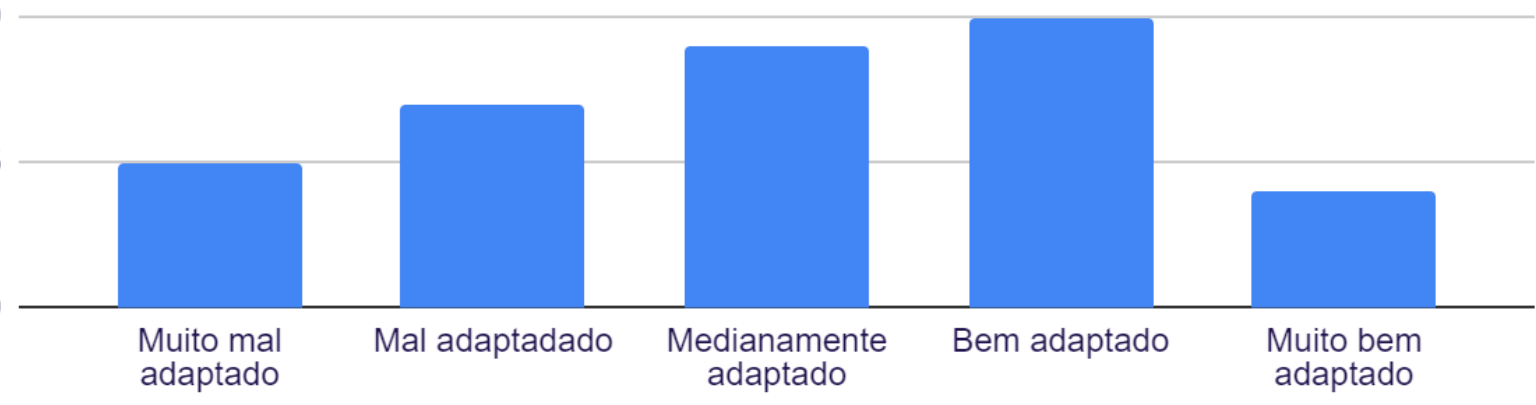

Fonte: Os autores, 2021

Ao se analisar o nível de adaptação destes ao modelo virtual, percebe-se uma uniformidade de opiniões dos estudantes, ainda que tendendo à má adaptação. Isso implica nas diversas maneiras com que os monitores afetaram os discentes.

A comunicação entre professores e alunos é de extrema importância para atualizações e execuções das atividades da matéria, e no período de ensino remoto virtual foram utilizados vários meios de comunicação pelos professores e monitores, sendo assim um aspecto relevante para a análise da pesquisa. 
Figura 05 - Avaliação dos discentes quanto à comunicação dos docentes para com a turma

\section{Comunicação}

20

15

10

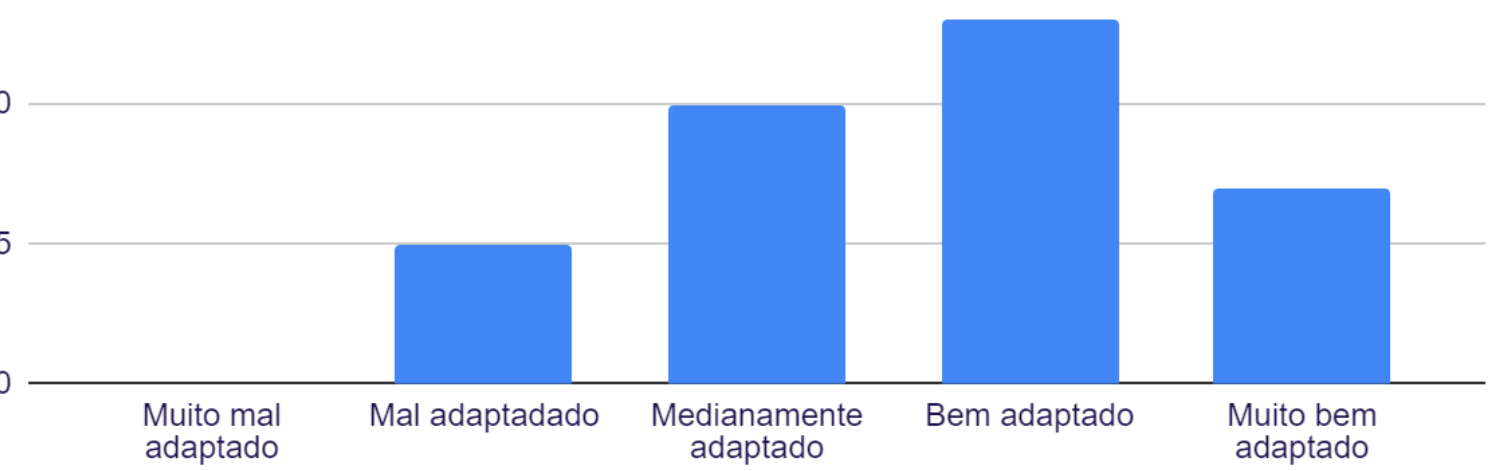

Fonte: Os autores, 2021

Como é perceptível, os canais de comunicação e as informações necessárias ao bom andamento das disciplinas foram bem avaliados pelos respondentes, com cerca de $57 \%$ de opiniões favoráveis.

Em se tratando da parcela do conteúdo prático do curso de Engenharia Civil, que é por si só bem abrangente, é notória a difícil adaptação ao modelo virtual. Ainda assim, diversas disciplinas da grade curricular do curso na UFPA se mantiveram aptas, mesmo com a impossibilidade de acesso a laboratórios e afins. Com isso, os autores julgaram bastante relevante questionar os discentes sobre essas disciplinas e, especificamente, sobre a adaptação da parte prática ao modelo virtual de ensino vigente. As respostas estão na Figura 06 a seguir.

Figura 06 - Avaliação dos discentes quanto à adaptação da parte prática das disciplinas ofertadas

\section{Parte Prática}

20

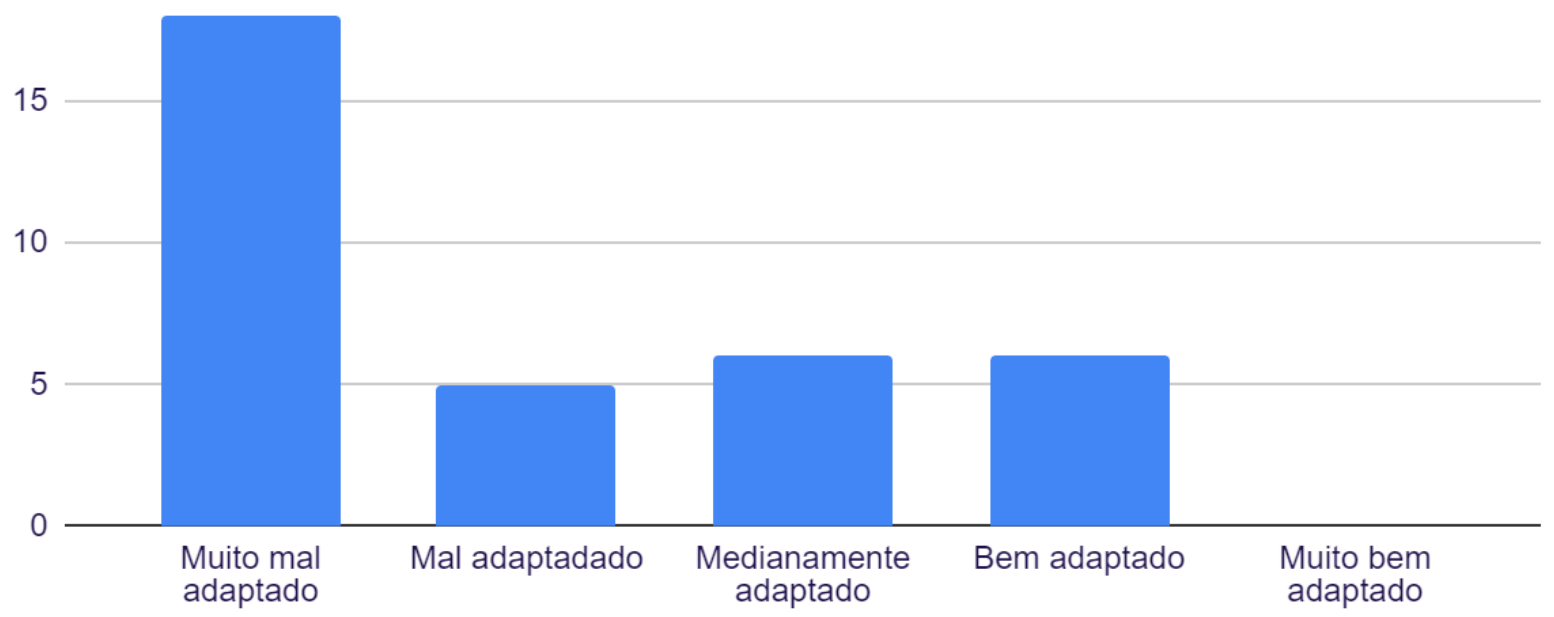

Fonte: Os autores, 2021 
Nota-se que a grande maioria dos discentes julgou a parte prática como muito mal adaptada, sendo que $65,7 \%$ dos respondentes são detratores dessa adaptação. Isso resulta em uma perda significante para 0 aprendizado dos discentes que optaram em seguir o curso no Ensino Remoto, uma vez que receberam um conteúdo aquém do desejado para a absorção adequada de conhecimento.

\subsection{Relações sobre o desempenho dos estudantes}

Os alunos respondentes desta pesquisa também foram questionados a respeito do seu desempenho durante o ERE. Quando perguntados sobre como consideravam seu próprio rendimento durante o Ensino Remoto em comparação ao ensino presencial, responderam conforme a Figura 07 abaixo.

Figura 07 - Avaliação do rendimento no ERE em comparação ao presencial

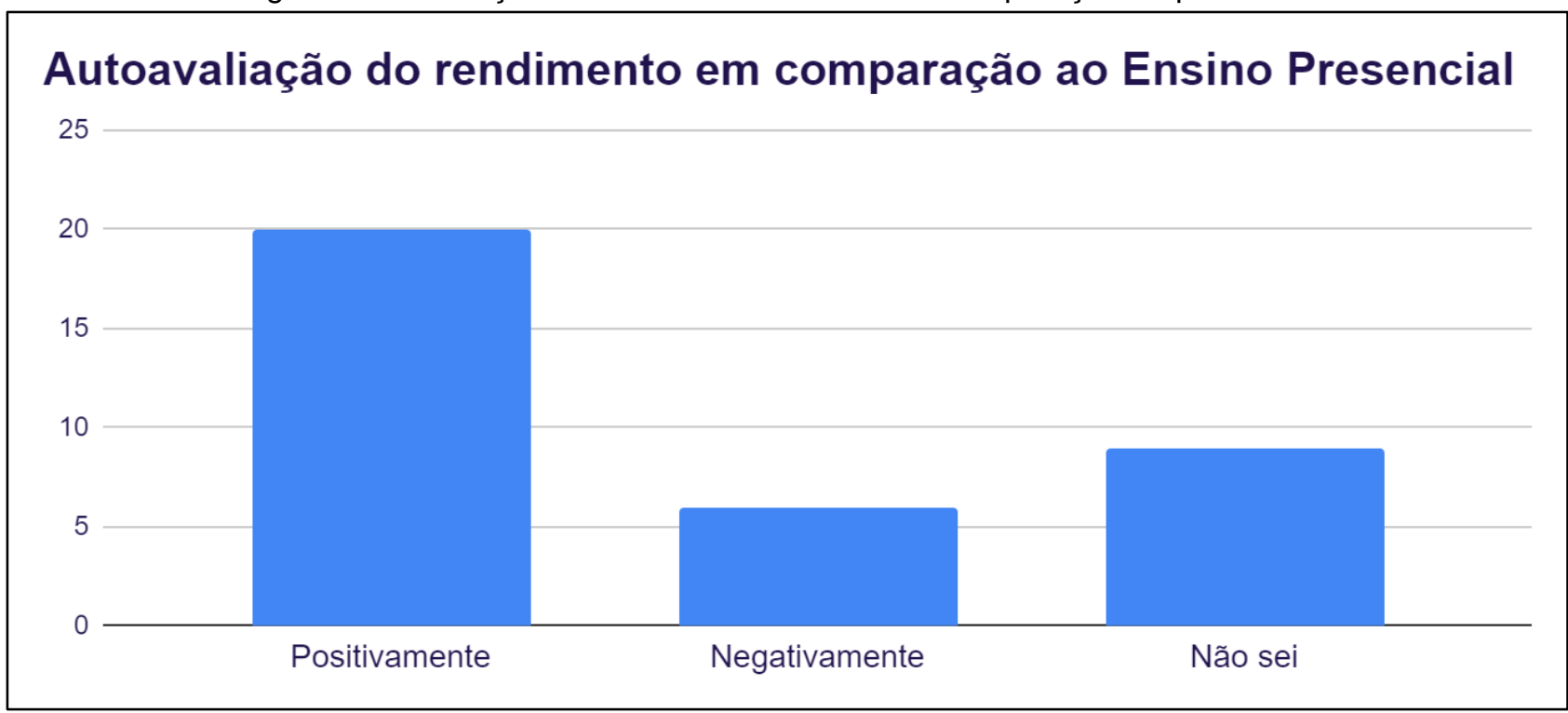

Fonte: Os autores, 2021

Nota-se, de acordo com modelo avaliativo adotado pelos autores, que $68,6 \%$ dos alunos relataram uma piora no seu rendimento durante o ERE, enquanto apenas $20 \%$ perceberam melhora no aprendizado.

Porém, é interessante notar que, quando questionados sobre como o modelo de ensino adotado afetou o CRG (Coeficiente de Rendimento Geral: média ponderada das notas obtidas nas disciplinas pela cara horária que estas dispunham) dos discentes, as respostas apontam para uma clara melhora, como mostra a Figura 08 abaixo. 
Figura 08 - Como o ERE afetou o CRG

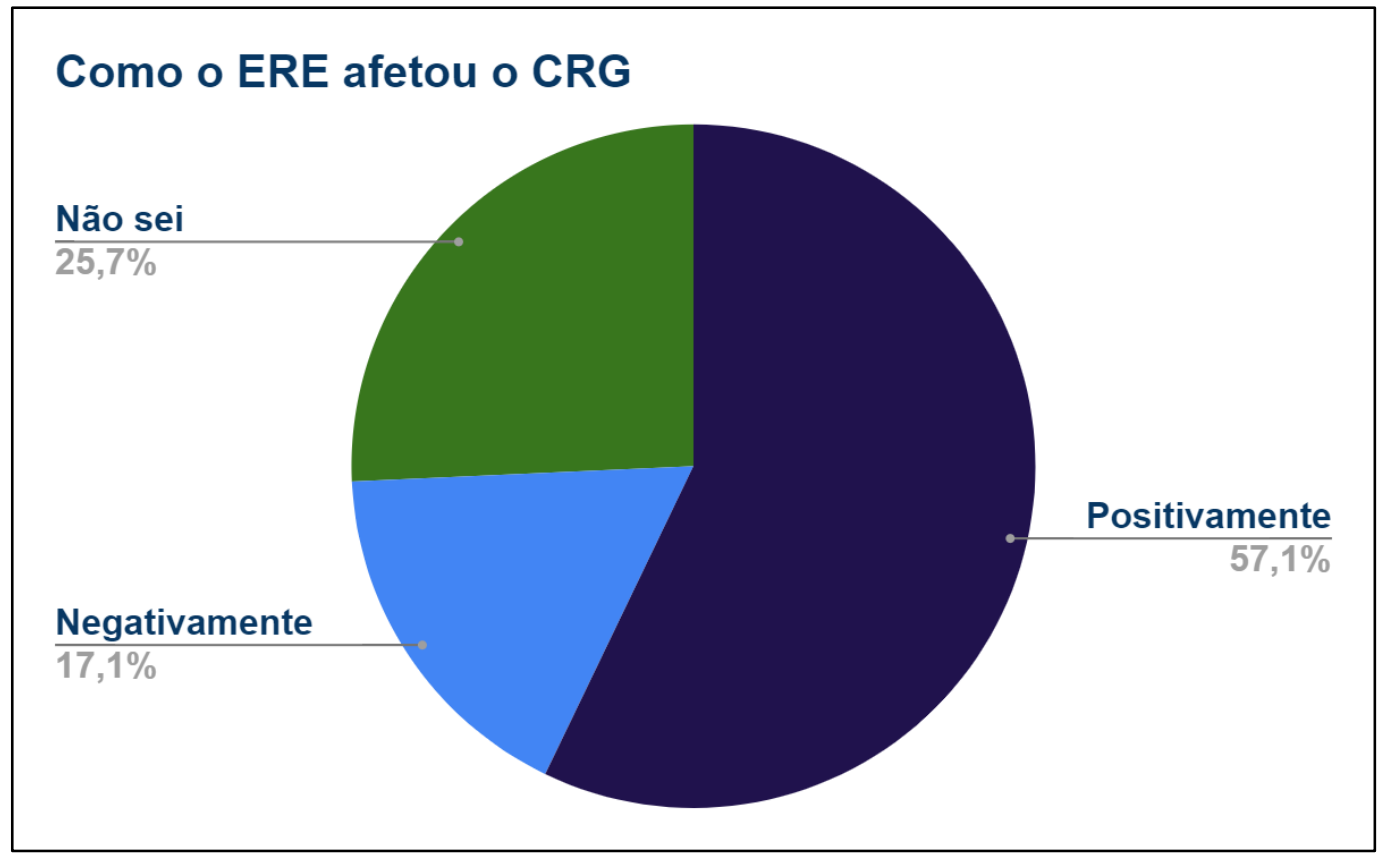

Fonte: Os autores, 2021

Os dados apontam para uma séria problemática para o ensino: Por mais que o conhecimento adquirido durante as disciplinas do Ensino Remoto tenha sido inferior ao outrora presencial, a nota obtida nas avaliações foi visivelmente maior, o que implica em alunos progredindo nos seus estudos sem possivelmente desenvolver os conhecimentos e habilidades necessárias ao exercício da profissão.

Ainda, foi perguntado se houve desistência de alguma disciplina, uma vez que, de acordo com as regras de vigência do ERE, tal desistência não acarretaria em maiores perdas ao discente. Contatou-se que cerca de metade dos alunos efetivamente desistiu de alguma disciplina, sendo que destes, 22,9\% abandonou 2 ou mais (Figura 09).

Figura 09 - Desistência de disciplinas durante o ERE

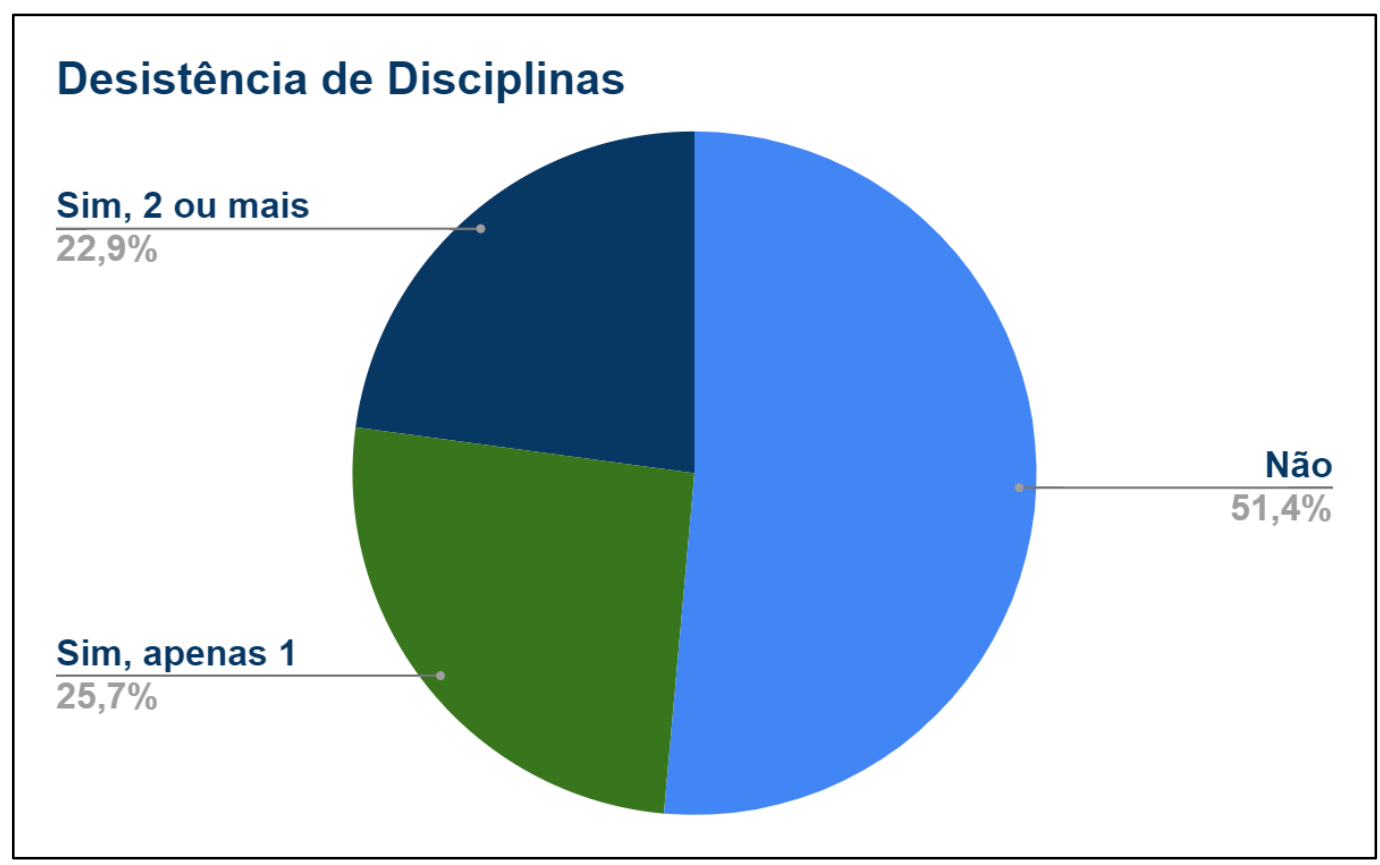

Fonte: Os autores, 2021 


\section{DISCUSSÃO}

\subsection{Correlações entre a adaptação dos professores}

Findado o período de coleta de dados do formulário e o início da análise de dados sobre os aspectos supracitados como principais pontos avaliativos sobre a adaptação dos docentes, os autores desenvolveram uma tabulação para os valores indicados pelos respondentes.

No primeiro, foram calculadas as médias aritméticas de cada um dos 6 parâmetros anteriores (Atuação dos monitores, Qualidade na comunicação docente-discentes, material bibliográfico disponibilizado, aplicação dos conceitos práticos, aplicação das avaliações e a metodologia durante as aulas). Tendo esses valores médios, foram atribuídos pesos para cada um dos indicadores (Tabela 01), para uma futura ponderação dos resultados.

Tabela 01 - Médias e pesos atribuídos aos parâmetros utilizados na pesquisa

\begin{tabular}{|l|c|c|}
\hline \multicolumn{1}{|c|}{ Parâmetro } & Médias & Peso \\
\hline Metodologia durante as aulas & 3,171 & 6 \\
\hline Aplicação das avaliações & 3,086 & 5 \\
\hline Aplicação dos conceitos práticos & 2,000 & 4 \\
\hline Material bibliográfico disponibilizado & 3,457 & 3 \\
\hline Qualidade na comunicação docente-discentes & 3,629 & 2 \\
\hline Atuação dos monitores & 3,029 & 1 \\
\hline
\end{tabular}

Fonte: Os autores, 2021

É visível que a parte de aplicações dos conceitos práticos foi um ponto de baixa para essa a majoração geral dos indicadores avaliados, sendo um ponto passível de para futuras revisões e otimização da praxe docente. Destarte, foi encontrada uma média ponderada de 3,005 para todos os valores avaliados, sendo a adaptação do Ensino Remoto Emergencial considerada pelos autores como medianamente adaptado, por se enquadrar aproximadamente no campo " 3 " da escala Likert utilizada durante a elaboração do formulário.

\subsection{Relações sobre o desempenho dos estudantes}

Nesta análise obtivemos um resultado interessante: apesar da maioria dos alunos apontarem decréscimo em seu ganho de conhecimento e rendimento, a maioria dos alunos obtiveram acréscimo em seus coeficientes de rendimento geral da universidade.

Estes dados podem soar contraditórios, porém podem ser melhor interpretados ao considerar os métodos avaliativos comumente utilizados na universidade: provas e exames. Desta forma, é possível classificar os estudantes em função de suas notas, os padronizando (Luckesi).

Em um estudo sobre métodos avaliativos durante o ensino remoto, Natália Andrade (bacharela em letras pela Universidade Federal de São Paulo) afirma que a avaliação escolar no formato de classificação e uniformização não contribui para o avanço da aprendizagem e para o crescimento intelectual dos alunos. 
Tendo em vista isso, é possível perceber que o CRG é um índice classificatório que não transparece o ganho de conhecimento do aluno. Portanto, apesar de os discentes de Engenharia Civil estarem se saindo bem em avaliações isoladas no formato remoto, seu ganho de conhecimento real está afetado. Tudo isso contribui para que os alunos se desmotivem, e essa falta de capacidade de se adaptar no formato e adquirir conhecimentos fez com que quase metade dos respondentes da pesquisa tenham desistido de pelo menos uma disciplina no semestre passado.

\section{CONSIDERAÇÕES FINAIS}

O curso de Engenharia Civil da UFPA é culturalmente tradicional e totalmente presencial há décadas, portanto, a súbita necessidade de modificação do método para algo remoto pegou de surpresa professores e alunos. Esta adaptação já está ocorrendo, porém não alcançou ainda sua totalidade, como mostram os dados aqui expostos.

Este momento atípico deixou explícita a grande necessidade de uma revisão nos métodos da Universidade, tanto de ensino quanto avaliativos, para que os professores se tornem mais flexíveis e versáteis, os alunos mais capazes de serem autodidatas e disciplinados e que os métodos avaliativos se tornem mais democráticos e realmente representem o aprendizado do aluno.

\section{REFERÊNCIAS}

ANDRADE, Natália Avilla. Como avaliar os alunos do ensino fundamental durante o período de ensino remoto. São Paulo, 2021.

GESTRADO. Trabalho docente em tempo de pandemia - Relatório técnico. Disponível em:

$<$ https://anped.org.br/sites/default/files/images/cnte_relatorio_da_pesquisa_covid_gestrad o_v02.pdf>. Acesso em 08 maio 2021.

LIKERT, R. A technique for the measurement of attitudes. Archives of Psychology, 22 140, 55. 1932

LUCKESI, Carlos Cipriano. Avaliação da Aprendizagem Escolar: estudos e proposições. 22 ed. São Paulo, 2011

OECD. (2020). Education at a glance. Paris

Disponível

em: $<$ https://download.inep.gov.br/acoes_internacionais/eag/documentos/2020/EAG_2020_V2 .pdf>. Acesso em 26 abril 2021. 


\title{
PERCEPTION OF LEARNING FROM THE DISCENTS OF UFPA DURING REMOTE TEACHING
}

\begin{abstract}
Throughout the COVID-19 pandemic, the Federal University of Pará adopted measures for the continuation of classes in a remote model. It consisted of adapting diverse parameters to virtual alternatives, by the university, professors, and students, without having enough time. Therefore, this article aimed to understand how students of Civil Engineering are dealing with this new scenario, as well as which factors most influence their performance. After analyzing the student's responses in the six parameters studied, the conclusions were that Emergency Remote Education (ERE) was considered by the authors moderately adapted, considering that it is already occurring and has not yet reached its totality.
\end{abstract}

Keywords: Remote Teaching. Pandemic. COVID-19. Performance. 